\title{
High incidence of hypertension-mediated organ damage in a series of Chinese patients with 17a- hydroxylase deficiency
}

\section{Zhiyuan Zhao}

Department of Endocrinology, NHC Key laboratory of Endocrinology (Peking Union Medical College Hospital), State Key Laboratory of Complex Severe and Rare Diseases, Peking Union Medical College Hospital, Peking Union Medical College, Chinese Academy of Medical Sciences, Beijing, 100730, China Lin Lu

Department of Endocrinology, NHC Key laboratory of Endocrinology (Peking Union Medical College Hospital), State Key Laboratory of Complex Severe and Rare Diseases, Peking Union Medical College Hospital, Peking Union Medical College, Chinese Academy of Medical Sciences, Beijing, 100730, China

\section{OU Wang}

Department of Endocrinology, NHC Key laboratory of Endocrinology (Peking Union Medical College Hospital), State Key Laboratory of Complex Severe and Rare Diseases, Peking Union Medical College Hospital, Peking Union Medical College, Chinese Academy of Medical Sciences, Beijing, 100730, China

\section{Xueyan Wu}

Department of Endocrinology, NHC Key laboratory of Endocrinology (Peking Union Medical College Hospital), State Key Laboratory of Complex Severe and Rare Diseases, Peking Union Medical College Hospital, Peking Union Medical College, Chinese Academy of Medical Sciences, Beijing, 100730, China

\section{Bang Sun}

Department of Endocrinology, NHC Key laboratory of Endocrinology (Peking Union Medical College Hospital), State Key Laboratory of Complex Severe and Rare Diseases, Peking Union Medical College Hospital, Peking Union Medical College, Chinese Academy of Medical Sciences, Beijing, 100730, China

\section{Wei Zhang}

Department of Endocrinology, NHC Key laboratory of Endocrinology (Peking Union Medical College Hospital), State Key Laboratory of Complex Severe and Rare Diseases, Peking Union Medical College Hospital, Peking Union Medical College, Chinese Academy of Medical Sciences, Beijing, 100730, China

\section{Xi Wang}

Department of Endocrinology, NHC Key laboratory of Endocrinology (Peking Union Medical College Hospital), State Key Laboratory of Complex Severe and Rare Diseases, Peking Union Medical College Hospital, Peking Union Medical College, Chinese Academy of Medical Sciences, Beijing, 100730, China Jiangfeng Mao

Department of Endocrinology, NHC Key laboratory of Endocrinology (Peking Union Medical College Hospital), State Key Laboratory of Complex Severe and Rare Diseases, Peking Union Medical College 
Hospital, Peking Union Medical College, Chinese Academy of Medical Sciences, Beijing, 100730, China

\section{Shi Chen}

Department of Endocrinology, NHC Key laboratory of Endocrinology (Peking Union Medical College Hospital), State Key Laboratory of Complex Severe and Rare Diseases, Peking Union Medical College Hospital, Peking Union Medical College, Chinese Academy of Medical Sciences, Beijing, 100730, China

\section{Anli Tong}

Department of Endocrinology, NHC Key laboratory of Endocrinology (Peking Union Medical College Hospital), State Key Laboratory of Complex Severe and Rare Diseases, Peking Union Medical College Hospital, Peking Union Medical College, Chinese Academy of Medical Sciences, Beijing, 100730, China Min Nie ( $\nabla$ nm_pumch@aliyun.com)

Department of Endocrinology, NHC Key laboratory of Endocrinology (Peking Union Medical College Hospital), State Key Laboratory of Complex Severe and Rare Diseases, Peking Union Medical College Hospital, Peking Union Medical College, Chinese Academy of Medical Sciences, Beijing, 100730, China

\section{Research Article}

Keywords: 17aHydroxylase/17,20-lyase deficiency, hypertension, hypertension-mediated organ damage

Posted Date: September 27th, 2021

DOI: https://doi.org/10.21203/rs.3.rs-933695/v1

License: (c) (i) This work is licensed under a Creative Commons Attribution 4.0 International License. Read Full License

Version of Record: A version of this preprint was published at Endocrine on January 14th, 2022. See the published version at https://doi.org/10.1007/s12020-021-02966-w. 


\section{Abstract \\ Objective}

To analyze the prevalence of hypertension-mediated organ damage (HMOD) and its relationship with enzyme activity of mutant CYP17A1 and other risk factors in patients with 17a-hydroxylase/17,20-lyase deficiency (17-OHD).

\section{Methods}

A total of 68 patients with 17-OHD were recruited in the Peking Union Medical Hospital from 2003 to 2021. The incidence of hypertension and HMOD was analyzed. CYP17A1 sequencing was performed for all patients and the enzyme activity of CYP17A1 mutant was determined by analyzing the characteristics of mutation itself and the functional data reported previously. A logistic regression model was employed to analyze the factors related to HMOD and the specific damaged organs in patients with 17-OHD.

\section{Result(s):}

Sixty-five patients (95.6\%) exhibited hypertension,32 of whom were diagnosed with HMOD in this 17-OHD cohort. c.985_987del TAC ins AA (p. Y329KfsX418) (53.8\%) and c.1459_1467del (p. del D487_F489) (11.4\%) were the top 2 mutations in this cohort, and no correlation was found between enzyme activity of mutant CYP17A1 and HMOD. Age, hypertension grade, and hypokalemia grade were independent risk factors for HMOD in $17-\mathrm{OHD}$ patients. The risk of HMOD increased by $27 \%$ for each additional year of age, 7.7-fold for each one-grade increase in hypertension level, and 1.7-fold for each grade of exacerbation of hypokalemia.

\section{Conclusion}

Patients with 17-OHD experience high incidence of HMOD. There was no correlation between the HMOD occurrence and enzyme activity of mutant CYP17A1.Age, hypertension grade, and hypokalemia grade are independent risks for the occurrence of HMOD.

\section{Introduction}

17a-hydroxylase/17,20-lyase deficiency (17-OHD) is a rare type of congenital adrenal hyperplasia and accounts for nearly $1 \%$ of the condition. $17-\mathrm{OHD}$ has an estimated incidence rate of $1: 50000$ and is an autosomal recessive disorder caused by biallelic mutations in the CYP17A1 gene[1-3]. This gene is located on 10q24.3, spans $6.6 \mathrm{~kb}$, consists of 8 exons and 7 introns, and is selectively expressed in the adrenal cortex and gonads[4]. Furthermore, the gene encodes the $\mathrm{P} 450 \mathrm{c} 17$ protein composed of 508 amino acids, with activities of both 17a-hydroxylase and 17, 20-lyase, which is a key enzyme in the 
biosynthesis of glucocorticoids and sex steroids[5]. Most mutations in CYP17A1 cause combined 17hydroxylase/17,20-lyase deficiency, while rare missense mutations cause isolated 17,20-lyase deficiency[6]. The former is further divided into complete or partial 17a-hydroxylase/17,20 lyase deficiency based on the extent of 17a-hydroxylase and 17, 20-lyase activities.

In humans, 17a-hydroxylase converts pregnenolone and progesterone to 17a-hydroxypregnenolone and 17a-hydroxyprogesterone (17-OHP), respectively, which are further altered to the androgen precursors dehydroepiandrosterone and androstenedione by 17,20-lyase. Owing to CYP17A1 gene mutation, the enzymatic activities of P450C17 are lost in patients with 17-OHD, and the glucocorticoid and/or sex hormone synthesis pathway is blocked. Insufficient cortisol synthesis and the compensatory increase in adrenocorticotropic hormone (ACTH) secretion stimulate the proliferation of adrenal cortical cells. Meanwhile, the lack of adrenal 17-hydroxylase activity forces steroidogenesis to corticosterone via 11deoxycorticosterone (DOC), which in humans is a very minor adrenal product and less potent than aldosterone. Thus, the excess DOC results in sodium retention and hypokalemia. When the sex hormone synthesis pathway is blocked, androgen insufficiency arrests the development of testes in men with 46, $\mathrm{XY}$ karyotype at an early stage, and the normal internal genital ducts and external genitalia cannot be formed. In women with 46, XX karyotype, the decrease in estrogen synthesis prevents puberty and results in primary amenorrhea[6, 7]. Consequently, low-renin hypertension, hypokalemia, female infantilism, primary amenorrhea, and male pseudohermaphroditism are the typical clinical features of $17-\mathrm{OHD}^{[1]}$. In the early stage, patients with 17-OHD often do not seek treatment owing to the lack of clinical manifestations and later consult the doctor for hypertension, hypokalemia, and sexual development abnormality $[8,9]$.

Hypertension-mediated organ damage (HMOD), previously termed as "target organ damage," refers to structural or functional changes in arteries or end organs (i.e., heart, brain, retina, kidney, and blood vessels) $[10,11]$. Early diagnosis is difficult, uncontrolled or poorly controlled HMOD significantly exacerbates the risk of end-organ damage[12-14]. Effective blood pressure lowering therapy can delay the progression of HMOD or even reverse it. Therefore, early identification of the condition and effective control of blood pressure is vital for hypertensive patients[15-17]. Hypertension is a coexisting problem in nearly $95 \%$ of the $17-\mathrm{OHD}$ patients ${ }^{[8]}$. It has been reported that $88 \%$ of the $17-\mathrm{OHD}$ cases are not diagnosed accurately until puberty or even later due to its extremely low incidence and varied clinical phenotypes[9]. Accordingly, some 17-OHD patients may develop HMOD because of poor blood pressure control and inappropriate disease management.

In this study, we analyzed the occurrence of HMOD and its relationship with enzyme activity of mutant CYP17A1 and other risk factors in 68 patients with 17a-hydroxylase/17,20-lyase deficiency (17-OHD) to augment our understanding of this rare disease.

\section{Subjects And Methods}

\section{Subjects}


A total of 68 Chinese patients with 17-OHD who were admitted to the Peking Union Medical College Hospital (Beijing) were recruited for this study between 2003 and 2021.

The inclusion criteria[6, 18, 19] for subjects with 17-OHD were based on the clinical manifestations and serum hormone levels as follows: 1. low cortisol level and high ACTH level, high gonadotropins, high progesterone $(P)$ and low testosterone $(T)$ or estradiol (E2). 2.Patients aged $\geq 18$ years at the clinical assessment.

This study was approved by the Ethics Committee for Human Research of Peking Union Medical College Hospital (No.JS-2111), and informed consents were obtained from all subjects participating in the study.

\section{Methods}

Detailed medical data pertaining to age, sex, height, weight, the highest blood pressure ever measured, blood pressure at the assessment of function of heart, kidney and retina, medication, imaging results (adrenal computed tomography (CT), pelvic and inguinal ultrasonography (USG), non-invasive transthoracic echocardiogram and resting standard 12-lead electrocardiography) were collected and analyzed. Funduscopy tests were conducted and interpreted by experienced ophthalmologists. Serum potassium $(\mathrm{K}+)$ and sodium $(\mathrm{Na}+)$, adrenocorticotropic hormone $(\mathrm{ACTH})$, plasma cortisol(F), luteinizing hormone ( $\mathrm{LH})$, follicle-stimulating hormone (FSH), estradiol (E2), progesterone $(\mathrm{P})$, testosterone $(\mathrm{T})$ and 17a-hydroxyprogesterone (17- OHP) at baseline and when assessing the function of heart, kidney and retina were measured.

\section{Laboratory test}

Plasma ACTH and serum cortisol at 8:00 AM were measured by chemiluminescence immunoassay (Advia Centaur XP, Bayer). Serum LH, FSH, estradiol $\left(E_{2}\right)$, progesterone $(P)$ and testosterone $(T)$ were measured with chemiluminescence (ACS:180; Automatic Chemiluminescence Systems, Bayer). 17hydroxyprogesterone (17- OHP) concentrations was determined by radioimmunoassay (Active 17a-OHP Progesterone DSL-5000, DSL). All hormone indexes above were measured in the context of absent hormone replacement therapy or drug withdrawal. The intra and inter assay coefficients of variation were $2.3 \%$ and $2.8 \%$ for $\mathrm{LH}, 3.9 \%$ and $4.5 \%$ for FSH, $5.6 \%$ and $6.6 \%$ for $\mathrm{T}, 6.7 \%$ and $8.2 \%$ for $\mathrm{ACTH}, 5.3 \%$ and $5.7 \%$ for cortisol, $3.9 \%$ and $5.6 \%$ for $17-\mathrm{OHP}$, respectively.

\section{PCR and sequencing of CYP17A1 gene}

Genomic deoxyribonucleic acid (DNA) from the peripheral blood leukocytes were obtained from all patients using a standard procedure (Omega Blood DNA Midi Kit, Omega Bio-Tek, USA). PCR combined with sequencing was employed to detect the mutations in all 8 exons and exon-intron boundaries of CYP17A1 gene, PCR primers were designed by the Oligo Primer Analysis Software (version 7.60, Molecular Biology Insights, Inc., USA) and amplification methods are described in Supplementary Information Table S1. PCR products were identified on $1.5 \%$ agarose gel electrophoresis and sent to the 
Beijing SinoGenoMas Company for purification and sequencing. The sequence was compared with the reference sequence NM_000102.4 of the CYP17A1 gene and NP_000093.1 of P450c17 protein through the NCBI website to ascertain the mutations.

\section{The enzymatic activity assessment of different CYP17A1 mutants}

The enzymatic activity corresponding to different mutations of CYP17A1 was assessed according to the mutation characteristics and the functional data reported by previous literature. The enzymatic activity of mutants caused by the variants seriously affecting the gene transcription and translation (e.g., small deletions/insertions, large deletions, nonsense mutation, frameshift mutation and splicing mutation) was considered "Nil" (completely abrogating the P450c17 protein function). The enzymatic activity of mutations verified on the previous literature was recognized as "Nil" (enzymatic activity abolished completely) or partial activity (residual enzyme function remained).

\section{Classification criteria for body-mass index, potassium grade and hypertension grade}

Body-mass index (BMI) was calculated as weight in $\mathrm{kg}$ divided by the square of height in meters, and was classified into the following categories: underweight $\left(<18.5 \mathrm{~kg} / \mathrm{m}^{2}\right)$, normal $\left(18.5-23.9 \mathrm{~kg} / \mathrm{m}^{2}\right)$, overweight $\left(24.0-27.9 \mathrm{~kg} / \mathrm{m}^{2}\right)$, and obese $\left(\geq 28.0 \mathrm{~kg} / \mathrm{m}^{2}\right)[20]$.

The definitions of serum potassium grade were as follows: normal serum potassium: $\geq 3.5 \mathrm{mmol} / \mathrm{L} ; \mathrm{mild}$ hypokalemia: $3.0-3.5 \mathrm{mmol} / \mathrm{L}$; moderate hypokalemia: $2.5-3.0 \mathrm{mmol} / \mathrm{L}$; severe hypokalemia: <2.5 $\mathrm{mmol} / \mathrm{L}^{[21-23]}$.

The definitions of hypertension grades were as follows[10, 24]: Grade 1 (mild): SBP 140-159 and/or DBP 90-99; Grade 2 (moderate) : SBP 160-179 and/or DBP 100-109; Grade 3 (severe): SBP $\geq 180$ and/or $\mathrm{DBP} \geq 110$.

\section{Classification and assessment of HMOD}

HMOD mainly involves the following organs[10]: heart: left ventricular hypertrophy, atrial fibrillation, and other arrhythmias, ischemic heart disease, and heart failure; kidney: proteinuria (decrease in albumincreatinine ratio) and renal dysfunction (decreased estimated glomerular filtration rate); retina: retinal hemorrhages, microaneurysms, hard exudates, cotton wool spots, and papilledema detected by fundoscopy.

The results of routine urine, renal function, electrocardiography, echocardiography, fundoscopy were obtained to evaluate the damage to the heart, kidney, retina organs.

\section{Statistical analysis}

SPSS (version 26, SPSS, IBM) statistical software package was used to analyze the data. A normality test was performed to determine whether the continuous variables conform to normal distribution. The 
normally distributed variables were represented as mean \pm standard deviation ( $\pm s)$, and the non-normally distributed variables were expressed as median (upper and lower quartiles) [M (Q1, Q3)]. Comparison between two groups was performed using independent t-test or Mann-Whitney $U$ test. Enumeration variables were expressed as cases $(n)$ and percentages and were compared by the Chi-square test or Fisher exact test. The risk factors for the occurrence of HMOD in patients with 17-OHD were analyzed by logistic univariate regression. Subsequently, logistic multivariate regression was employed to estimate the independent risk factors for the occurrence of HMOD and the specific damaged organs in the patients. $P$ value less than 0.05 was considered statistically significant.

\section{Results}

\section{Mutation analysis for CYP17A1 gene}

Sanger sequencing of 66 patients identified 36 different mutations (Table 1). The mutation c.985_987delTACinsAA (p. Y329KfsX418) in Exon 6 was the most common one among the Chinese 17OHD patients, accounting for $53.8 \%$ of the mutant alleles (71/132), followed by the mutation c.1459_1467del GACTCTTTC (p. del D487_F489) (11.4\%,15/132). The majority of patients showed compound heterozygote, while 29 patients were homozygote, of which 23 showed the c.985_987delTACinsAA(Y329KfsX418) homozygote, 4 showed the c.1459_1467del GACTCTTTC (D487_F489del) homozygote and 2 showed the other mutant homozygote, respectively. According to previous literature $^{[19,25-31]}$, the enzymatic activity caused by different mutations is also listed herein.

\section{The clinical characteristics of 17-OHD patients}

Among the 68 patients with 17-OHD, 36(52.9\%) had 46, XX karyotype, and 32(47.1\%) had 46, XY karyotype. The levels of $\mathrm{P}, \mathrm{FSH}, \mathrm{LH}$, and ACTH were higher than the upper normal range, while the levels of $\mathrm{T}, \mathrm{E}_{2}, 17-\mathrm{OHP}$, and serum-free cortisol were lower than the normal low range. There was no significant statistical difference in each index between the genetic male (46XY) and the genetic female (46XX) group (Table 2). No uterine or ovarian structures were found on USG in patients with $46, X Y$ karyotype, and 28 patients (87.5\%) had undergone gonadectomy. Among the patients with 46, XX karyotype, 19(52.8\%) showed "infantile uterus" or "primordial uterus" on pelvic USG, and 17 (47.2\%) did not have obvious uterine and ovarian structures despite the facts that they had not undergone prior hysterectomy or gonadectomy. Among the 68 patients with 17-OHD, 41 had undergone an adrenal CT scan, and 39 $(95.1 \%)$ of them exhibited unilateral or bilateral thickened adrenal glands.

\section{Comparison of clinical characteristics of 17-OHD patients in the HMOD and non-HMOD groups}

The age of the patients in the HMOD group was higher than that of the non-HMOD group $(26.00(24.00,30.00)$ years and $20.50(19.00,25.00)$ years, respectively), the blood pressure grade of the HMOD group was higher than that of the non-HMOD group, and the hypokalemia grade of the HMOD group was higher than that of the non-HMOD group $(p<0.05)$. There was no statistically significant difference in other variables between the two groups (Table 3 ). 
Regarding to the medication received, the patients number receiving antihypertensive agents or glucocorticoid in the HMOD group and the non-HMOD group did not show any statistically significant difference. No statistical difference was noted in the blood pressure value and the serum potassium level when assessing organs damage in our hospital.

\section{The occurrence of hypertension and HMOD in 17-OHD patients}

Among the 68 patients with 17-OHD, 3(4.4\%) were normotensive and the remaining $65(95.6 \%)$ were hypertensive. Among the patients with hypertension, 6 (9.2\%) belonged to Grade 1, 21(32.3\%) to Grade 2, and $38(58.5 \%)$ to Grade 3 . After the diagnosis of hypertension, 26 patients (40.0\%) did not regularly monitor their blood pressure or accept therapy at all, 20(30.8\%) received antihypertensive drugs alone to control blood pressure, 15 (23.1\%) took glucocorticoids combined with antihypertensive drugs to control their blood pressure, including $9(13.8 \%)$ patients who could not achieve well controlled blood pressure with antihypertensive drugs alone until they were administrated with glucocorticoids. Moreover,4(6.2\%) patients could bring their blood pressure to the normal levels with glucocorticoid monotherapy (Figure 1). Calcium channel blocker (i.e., Nifedipine GITS and Amlodipine Besylate) and the aldosterone receptor antagonists spironolactone were commonly prescribed antihypertensive agents, only 5 patients took spironolactone to control the blood pressure. Among the 17-OHD patients, 32 were identified to have HMOD $(32 / 68,47.1 \%)$, while the remaining 36 did not have HMOD $(36 / 68,52.9 \%)$ (Table 4). In the HMOD group, 3 patients had three organs damage, 14 had two organs damage, and 15 had one organ damage (Table 4). The kidney and the eyes were the most frequently affected organs, with more than half of the patients ( $56.3 \%$ and $68.8 \%$, respectively) in the HMOD group suffering from the dysfunction of these two organs.

\section{HMOD related risk factors in patients with 17-OHD}

Age, hypertension grade, and hypokalemia grade were the independent risk factors for HMOD in the patients with 17-OHD, as inferred from multivariate logistic regression analysis (Table 5). The risk of HMOD increased by $27 \%$ for each additional year of age, 7.7 -fold for each one-grade increase in hypertension level, and 1.7-fold for each grade of exacerbation of hypokalemia.

We further analyzed the risk factors associated with specific organ damage in 17-OHD patients and found that the hypokalemia grade was the independent risk factors for both heart damage (Supplementary Information Table S2) and kidney damage (Supplementary Information Table S3), the age was the independent risk factors for retina (Supplementary Information Table S4).

\section{Discussion}

This study, for the first time, investigated the occurrence of HMOD in a large series of patients with 17OHD from a single medical center. Our findings demonstrated that hypertension occurred in $95.6 \%$ of the patients with 17-OHD, $49.2 \%$ of whom had coexisting HMOD. Age, hypertension grade, and hypokalemia grade were the independent risk factors for HMOD in the patients. 
From the perspective of pathogenesis, CYP17A1 gene mutation in the patients with 17-OHD resulted in the overproduction of aldosterone precursors such as DOC and corticosterone. Previous studies have shown that hyperaldosteronemia can not only cause metabolic disorders and target organ damage by raising the blood pressure but also affect the blood vessels, myocardium, kidney, and other organs ${ }^{\text {[32]. }}$ Whether DOC could cause damage to the relevant organs apart from its strong effect on the blood pressure remains to be investigated.

Searching the functional verification data of various CYP17A1 gene mutations in previous literature, we attempted to determine the relationship between the HMOD occurrence and the residual enzyme activity. Theoretically, the patients affected by mutations retaining partial enzyme activity tended to demonstrate milder clinical phenotypes and lesser risk of HMOD. We could not reach this conclusion possibly because most 17-OHD patients were confirmed to have complete combined 17-hydroxylase/17,20-lyase deficiency by genetic testing, where the mutations nearly abolished all the enzymatic activity, and the accessible mutations retaining partial enzyme activity are were very few $(5 / 60,8.3 \%)$ to show any statistical difference.

A study on middle-aged hypertensive individuals established that the self-reported age of hypertension onset, which can reflect the duration of hypertension, is associated with HMOD[33]. Because the signs and symptoms of patients with 17-OHD are often overlooked, they do not consult a doctor at an early age and many are not diagnosed until adolescence or even later. In our study, the age of clinical assessment could indicate the moment of HMOD detection and the duration of hypertension. The older the patient, the longer may be the duration of natural disease and the higher the risk of HMOD.

Previous studies on the incidence of target organ damage in the Chinese population with essential hypertension have shown that severe hypertension (Grade 3) is an independent risk factor for damage to the heart, brain, kidney, and other organs[34]. Another study has revealed that 24-hour systolic blood pressure is a major determinant of target organ damage irrespective of age and target organ, whereas 24hour diastolic blood pressure is only associated with kidney damage below middle age[35]. The hypertension grade is a stratified index based on the values of systolic and diastolic blood pressure of the most severe hypertension ever found, which can reflect the severity of the disease. A previous investigation has shown that the severity of hypertension, represented by the hypertension grade, is an important risk factor for target organ damage[36]. Patients with 17-OHD who have a higher hypertension grade usually have more severe hypertension, and they tend to have a higher risk for HMOD.

The main physiological functions of serum potassium are maintaining cell metabolism, regulating the osmotic pressure and acid-base balance, and supporting neuromuscular stress and normal functioning of the myocardium. Severe hypokalemia may present with somnolence, coma, and other nervous system manifestations. Besides, the condition can contribute to degeneration and necrosis of renal tubular epithelial cells, further leading to decreased function of urine concentration and hypokalemic nephropathy[37, 38]. Furthermore, hypokalemia can directly cause extremely dangerous ventricular fibrillation and cardiac arrest $[39,40]$. In this study, hypokalemia grade classified according to the lowest 
potassium concentration ever tested was found to be an independent risk factor for HMOD in patients with 17-OHD. In addition to the fact that hypokalemia per se can affect the functioning of various organs, the degree of hypokalemia depends on the overproduction of mineralocorticoids and can indicate the severity of 17-OHD. The lowering of serum potassium is the outcome of a serious loss of the enzymatic function of P450C17 and usually implies a high severity of the disorder. Therefore, hypokalemia is of definite clinical significance in the evaluation of HMOD induced by 17-OHD.

We found that among the patients with 17-OHD, between the initial diagnosis of hypertension and the assessment of HMOD, $40.0 \%$ of the hypertensive subjects did not regularly take antihypertensive drugs and that $60.0 \%$ were administrated antihypertensive drugs alone, glucocorticoid combined with antihypertensive drugs, or glucocorticoid alone to control their blood pressure. As hypertension in patients with 17-OHD is caused by the overproduction of mineralocorticoids (DOC, corticosterone) owning to the blockage of glucocorticoid synthesis, timely replacement therapy with corticosteroids can effectively inhibit the excessive secretion of ACTH and alleviate the accumulation of precursor substances (i.e., progesterone and pregnenolone). Hypertension can be relieved or even normalized in a majority of the patients with 17-OHD. In our study, blood pressure control could not be achieved in nine hypertensive patients $(13.8 \%)$ who were treated with antihypertensive drugs alone until they were administrated with glucocorticoids, whereas the blood pressure was controlled in four patients $(6.2 \%)$ with glucocorticoid monotherapy. These results indicate that addressing the etiology is very important in controlling the blood pressure of the patients. Our study suggests that the blood pressure management status of the 17-OHD patients is not optimistic and warrants much more attention and standardized treatment.

In our study, the number of patients receiving antihypertensive agents or glucocorticoids in the HMOD and the NO HMOD groups didn't show any statistically significant difference, and the medication intervention was not proven to be the risk factor for HMOD, which may because, irrespective of in the HMOD or the NO HMOD groups, nearly two thirds hypertensive patients had received antihypertensive agents or glucocorticoids to lower blood pressure level. To make matter worse, their blood pressure was not well controlled within the normal range according to the blood pressure value assessed in our hospital. All things considered, the hypertension status of 17-OHD patients in the present cohort was not controlled well before the assessment of HMOD, hence we could not draw any conclusion about whether the medication intervention benefitted organ protection. According to previous studies, the organ condition of some patients with untreated essential hypertension who have preexisting HMOD can be improved if their blood pressure is maintained within the normal range for 3 years [17]. In patients with 17$\mathrm{OHD}$, long-term follow-up and in-depth studies are needed to determine if achieving blood pressure control could improve the occurrence and development of HMOD.

\section{Limitations}

There are some limitations to this research. First, this was a retrospective study; hence, the medical information, including the initial clinical manifestations of 17-OHD and the relevant HMOD might have 
been affected by recall bias. Furthermore, there is a possibility of missing data due to previously limited examination conditions and uncontrollable patient willingness, for example, the lack of assessment of damage to the brain and the great vessels. These factors might have resulted in an underestimation of the incidence of HMOD in the patients with 17-OHD. Second, since most patients were not tested for DOC, the DOC level was not included in the analysis of factors associated with hypertension and HMOD, which may have further led to the incomplete analysis of the related risk factors for hypertension and HMOD in 17-OHD patients.

\section{Conclusion}

Taken together, hypertension is a common clinical manifestation of 17-OHD, patients with 17-OHD have a high incidence of HMOD. There was no correlation between the HMOD occurrence and the enzyme activity of mutant CYP17A1. Age, hypertension grade, and hypokalemia grade are the independent risk factors for the occurrence of HMOD.

\section{Declarations}

\section{Acknowledgement}

We thank the subjects and their family members for their participation in this research study.

\section{Financial Support}

This work was supported by the National Natural Science Foundation of China (Grant No. 81971375 and 81771576), Natural Science Foundation of Beijing (Grant No. 7212080 and 7202151 ).

\section{Conflicts of interest/Competing interests}

The authors declare that they have no conflict of interest.

\section{Authors' contributions}

MN, LL and OW made substantial contributions to conception and design of data; clinical data was collected by XW, SC, JFM, ALT and XYW, experiments were performed by WZ and ZYZ, data statistics and analysis were completed by $Z Y Z$ and $B S$, manuscript was written by $Z Y Z$ and $M N, X Y W$ and JFM revised the manuscript critically for important intellectual content. All authors have given final approval of the version to be published and everyone agreed to be accountable for all aspects of the work in ensuring that questions related to the accuracy or integrity of any part of the work are appropriately investigated and resolved.

\section{Ethics approval}


This study was approved by the Ethics Committee for Human Research of Peking Union Medical College Hospital (No.JS-2111), and informed consents were obtained from all subjects participating in the study.

\section{Consent to participate}

Written informed consent to participate in the study were obtained from all the participants or legal guardian participating in the study.

\section{Consent for publication}

Written informed consent for publication of their clinical details and/or clinical images was obtained from the all the patients or legal guardians participating in this study.

\section{References}

1. D. EL-MAOUCHE, W. ARLT, MERKE D P. Congenital adrenal hyperplasia [J]. Lancet 390(10108), 21942210 (2017)

2. E.S.P.I.N.E. ESPINOSA-HERRERA F, TITO-ALVAREZ A M et al., A report of congenital adrenal hyperplasia due to 17alpha-hydroxylase deficiency in two 46,XX sisters [J]. Gynecol. Endocrinol. 36(1), 24-29 (2020)

3. KATER C E, BIGLIERI E G, Disorders of steroid 17 alpha-hydroxylase deficiency [J]. Endocrinol. Metab. Clin. North Am. 23(2), 341-357 (1994)

4. M. CHUNG B C, PICADO-LEONARD J, HANIU et al., Cytochrome P450c17 (steroid 17 alphahydroxylase/17,20 lyase): cloning of human adrenal and testis CDNAs indicates the same gene is expressed in both tissues [J]. Proc Natl Acad Sci U S A 84(2), 407-411 (1987)

5. MILLER W L, AUCHUS R J, GELLER D H, The regulation of 17,20 lyase activity [J]. Steroids 62(1), 133-142 (1997)

6. R.J. AUCHUS. Steroid 17-hydroxylase and 17,20-lyase deficiencies, genetic and pharmacologic [J]. J Steroid Biochem Mol Biol, 2017, 165(Pt A): 71 - 8

7. T. YANASE, SIMPSON E R, WATERMAN M, R. 17 alpha-hydroxylase/17,20-lyase deficiency: from clinical investigation to molecular definition [J]. Endocr. Rev. 12(1), 91-108 (1991)

8. R. FONTENELE, COSTA-SANTOS M, KATER, C E. 17alpha-HYDROXYLASE DEFICIENCY IS AN UNDERDIAGNOSED DISEASE: HIGH FREQUENCY OF MISDIAGNOSES IN A LARGE COHORT OF BRAZILIAN PATIENTS [J], Endocr Pract 24(2), 170-178 (2018)

9. L. HINZ, D. PACAUD, KLINE G. Congenital adrenal hyperplasia causing hypertension: an illustrative review [J]. J Hum Hypertens 32(2), 150-157 (2018)

10. B. WILLIAMS, G. MANCIA, W. SPIERING et al., 2018 ESC/ESH Guidelines for the management of arterial hypertension [J]. Eur. Heart J. 39(33), 3021-3104 (2018)

11. T. UNGER, C. BORGHI, F. CHARCHAR et al., 2020 International Society of Hypertension global hypertension practice guidelines [J]. Journal of Hypertension, 2020, 38( 
12. T. GREVE S V, BLICHER M K, SEHESTEDT et al., Effective risk stratification in patients with moderate cardiovascular risk using albuminuria and atherosclerotic plaques in the carotid arteries [J]. J Hypertens 33(8), 1563-1570 (2015)

13. A. PERRONE-FILARDI P, COCA, M. GALDERISI et al., Noninvasive cardiovascular imaging for evaluating subclinical target organ damage in hypertensive patients: a consensus article from the European Association of Cardiovascular Imaging, the European Society of Cardiology Council on Hypertension and the Euro [J]. J. Hypertens. 35(9), 1727-1741 (2017)

14. VAN DEN BORN B H, LIP G Y H, BRGULJAN-HITIJ J et al., ESC Council on hypertension position document on the management of hypertensive emergencies [J]. Eur Heart $\mathrm{J}$ Cardiovasc Pharmacother 5(1), 37-46 (2019)

15. R. DE SIMONE G, DEVEREUX R B, IZZO et al., Lack of reduction of left ventricular mass in treated hypertension: the strong heart study [J]. J Am Heart Assoc 2(3), e000144 (2013)

16. M.T. LøNNEBAKKEN, R. IZZO, C. MANCUSI et al., Left Ventricular Hypertrophy Regression During Antihypertensive Treatment in an Outpatient Clinic (the Campania Salute Network) [J]. J Am Heart Assoc, 2017, 6(3)

17. H. TRIANTAFYLLIDI, A. BE NAS D, SCHOINAS et al., Hypertension-mediated organ damage regression associates with blood pressure variability improvement three years after successful treatment initiation in essential hypertension [J]. Journal of Clinical Hypertension, 2021, 5)

18. M. ZHANG, S. SUN, Y. LIU et al., New, recurrent, and prevalent mutations: Clinical and molecular characterization of 26 Chinese patients with 17alpha-hydroxylase/17,20-lyase deficiency [J]. J Steroid Biochem Mol Biol, 2015, 150(11 - 6

19. C.S. MARIVANIA, R.J. KATER C E, AUCHUS, Two Prevalent CYP17 Mutations and GenotypePhenotype Correlations in 24 Brazilian Patients with 17-Hydroxylase Deficiency [J]. Journal of Clinical Endocrinology \& Metabolism, 2004, 1): 49-60

20. X. ZHANG, M. ZHANG, Z. ZHAO et al., Geographic Variation in Prevalence of Adult Obesity in China: Results From the 2013-2014 National Chronic Disease and Risk Factor Surveillance [J]. Ann. Intern. Med. 172(4), 291-293 (2020)

21. F.J. GENNARI, Hypokalemia [J]. N. Engl. J. Med. 339(7), 451-458 (1998)

22. W.O.U.K.N. VIERA A J, Potassium Disorders: Hypokalemia and Hyperkalemia [J]. Am Fam Physician 92(6), 487-495 (2015)

23. J. ASHURST, S.E.R.G.E.N.T.B.R. SERGENT S R, Evidence-Based Management Of Potassium Disorders In The Emergency Department [J]. Emerg Med Pract 18(11), 1-24 (2016)

24. CHINESE HYPERTENSION PREVENTION AND TREATMENT GUIDELINES REVISION COMMITTEE HU C, CARDIOLOGY BRANCH OF, CHINESE MEDICAL ASSOCIATION, Chinese Guidelines for the Prevention and Treatment of Hypertension (2018 Revised Edition) [J]. Chin J Cardiovasc Med 24(1), 25 (2019)

25. R.J. MARSH C A, AUCHUS, Fertility in patients with genetic deficiencies of cytochrome P450c17 (CYP17A1): combined 17-hydroxylase/17,20-lyase deficiency and isolated 17,20-lyase deficiency [J]. 
Fertil. Steril. 101(2), 317-322 (2014)

26. J. WANG Y P, LI, J.X. LI et al., Three novel CYP17A1 gene mutations (A82D, R125X, and C442R) found in combined 17a-hydroxylase/17,20-lyase deficiency [J]. Metabolism 60(10), 1386-1391 (2011)

27. N. LAFLAMME, J. LEBLANC J F, MAILLOUX et al., Mutation R96W in cytochrome P450c17 gene causes combined 17 alpha-hydroxylase/17-20-lyase deficiency in two French Canadian patients [J]. J Clin Endocrinol Metab 81(1), 264-268 (1996)

28. N. NáJERA, N. GARIBAY, Y. PASTRANA et al., Loss of cytochrome P450 17A1 protein expression in a 17alpha-hydroxylase/17,20-lyase-deficient $46, \mathrm{XY}$ female caused by two novel mutations in the CYP17A1 gene [J]. Endocr Pathol 20(4), 249-255 (2009)

29. VAN DEN AKKER E L, KOPER J W, BOEHMER A L et al., Differential inhibition of 17alpha-hydroxylase and 17,20-lyase activities by three novel missense CYP17 mutations identified in patients with P450c17 deficiency [J]. J Clin Endocrinol Metab 87(12), 5714-5721 (2002)

30. K.A.N.G.M. KIM Y M, J.H. CHOI et al., A review of the literature on common CYP17A1 mutations in adults with 17-hydroxylase/17,20-lyase deficiency, a case series of such mutations among Koreans and functional characteristics of a novel mutation [J]. Metabolism 63(1), 42-49 (2014)

31. K. MIURA, K. YASUDA, T. YANASE et al., Mutation of cytochrome P-45017 alpha gene (CYP17) in a Japanese patient previously reported as having glucocorticoid-responsive hyperaldosteronism: with a review of Japanese patients with mutations of CYP17 [J]. J Clin Endocrinol Metab 81(10), 37973801 (1996)

32. S. ARDHANARI, R. KANNUSWAMY, K. CHAUDHARY et al., Mineralocorticoid and apparent mineralocorticoid syndromes of secondary hypertension [J]. Adv Chronic Kidney Dis 22(3), 185-195 (2015)

33. K. SUVILA, MCCABE E L, LIMA J A C et al., Self-reported Age of Hypertension Onset and Hypertension-Mediated Organ Damage in Middle-Aged Individuals [J]. Am. J. Hypertens. 33(7), 644651 (2020)

34. H. CUI, F. WANG, FAN L, et al. Association factors of target organ damage: analysis of 17,682 elderly hypertensive patients in China [J]. Chin Med J (Engl) 124(22), 3676-3681 (2011)

35. Y. WEI F F, LI, L. ZHANG et al., Association of target organ damage with 24-hour systolic and diastolic blood pressure levels and hypertension subtypes in untreated Chinese [J]. Hypertension 63(2), 222228 (2014)

36. NELISSEN H E, HENDRIKS M E, WIT F W N, M et al., Target organ damage among hypertensive adults in rural Nigeria: a cross-sectional study [J]. J. Hypertens. 32(3), 487-494 (2014)

37. S. REUNGJUI, W. RONCAL C A, SATO et al., Hypokalemic nephropathy is associated with impaired angiogenesis [J]. J Am Soc Nephrol 19(1), 125-134 (2008)

38. RELMAN A S, SCHWARTZ W B. The kidney in potassium depletion [J]. Am. J. Med. 24(5), 764-773 (1958)

39. DYCKNER T, Relation of cardiovascular disease to potassium and magnesium deficiencies [J]. Am. J. Cardiol. 65(23), 44k-44k6k (1990) 
40. D.J. PALMER B F, CLEGG, Physiology and pathophysiology of potassium homeostasis [J]. Adv Physiol Educ 40(4), 480-490 (2016)

\section{Tables}

Table 1 summary of CYP17A1 gene mutation in 66 cases

a: From references, ND: Not determined区Nil: complete deficiency of CYP17A1

Table 2 clinical characteristics of 17-OHD patients 
Mutation

DNA level

(c.157_159/c.160_162) del TTC

c. $245 \mathrm{C}>\mathrm{A}$

c. $286 \mathrm{C}>\mathrm{T}$

c. $297+2 T>C$

c. $298 \otimes 1 \mathrm{G}>\mathrm{A}$

c.302delC

c. $436 \otimes 1 \mathrm{G}>\mathrm{T}$

c. $437 \rrbracket 1 \mathrm{G}>\mathrm{C}$

c. $445 \mathrm{G}>\mathrm{A}$

c. $626 \mathrm{~T}>\mathrm{G}$

(c.662_666\&c.666+7) del

TGAAGGTGAGAT ins

CCACCCTGCTTTCA

\begin{tabular}{|c|c|c|c|c|}
\hline c.707T>G & V236G & Exon4 & Nil & $1 / 1$ \\
\hline c.775_776del AT & $1259 \mathrm{Hfs} \times 274$ & Exon5 & Nil & $3 / 3$ \\
\hline c.932_939delTTAAATGG & V311DfsX330 & Exon5 & Nil & $1 / 1$ \\
\hline $\begin{array}{l}\text { (c.973_975/976_978/979_981) } \\
\text { del GAA }\end{array}$ & $\begin{array}{l}\text { Del K } \\
(325 / 326 / 327)\end{array}$ & Exon6 & Nil & $1 / 1$ \\
\hline c.985_987delTACinsAA & Y329KfsX418 & Exon6 & Nil & $79 / 52$ \\
\hline c. $1039 \mathrm{C}>\mathrm{T}$ & R347C & Exon6 & $13.6 \%[29]$ & $1 / 1$ \\
\hline c. 1072 C>T & R358X & Exon6 & Nil & $2 / 2$ \\
\hline c.1080_1081del GC>A & L361FfsX418 & Exon6 & Nil & $1 / 1$ \\
\hline c.1082T『C & L361P & Exon6 & ND & $2 / 2$ \\
\hline c. $1084 C>T$ & R362C & Exon6 & $\mathrm{Nil}^{[19,25]}$ & $1 / 1$ \\
\hline c. $1085 \mathrm{G}>\mathrm{A}$ & $\mathrm{R} 362 \mathrm{H}$ & Exon6 & $\mathrm{Nil}^{[28]}$ & $1 / 1$ \\
\hline c.1117delC & H373TfsX418 & Exon6 & Nil & $1 / 1$ \\
\hline c. $1118 A>T$ & H373L & Exon6 & $\operatorname{Nil}[25,30]$ & $2 / 2$ \\
\hline c.1181_1183del TCA & del N (394) & Exon7 & Nil & $1 / 1$ \\
\hline
\end{tabular}




\begin{tabular}{|c|c|c|c|c|}
\hline c.1193 C>T & A398V & Exon7 & ND & $1 / 1$ \\
\hline c. $1217 \mathrm{G}>\mathrm{A}$ & W406X & Exon7 & Nil & $1 / 1$ \\
\hline c.1221insA & H407QfsX415 & Exon7 & Nil & $1 / 1$ \\
\hline c. $1226 \mathrm{C}>\mathrm{T}$ & P409L & Exon7 & ND & $1 / 1$ \\
\hline c. $1226 C>G$ & P409R & Exon7 & $\mathrm{Nil}{ }^{[25]}$ & $2 / 1$ \\
\hline c. $1247 \mathrm{G}>\mathrm{A}$ & $\mathrm{R} 416 \mathrm{H}$ & Exon8 & $\mathrm{Nil}{ }^{[25]}$ & $1 / 1$ \\
\hline c.1253 T>A & L418X & Exon8 & Nil & $1 / 1$ \\
\hline c.1459_1467del GACTCTTTC & del D487_F489 & Exon8 & Nil & $15 / 11$ \\
\hline c.1466 del T & F489SfsX491 & Exon8 & Nil & $1 / 1$ \\
\hline c. $1486 \mathrm{~T}>\mathrm{C}$ & $\mathrm{R} 496 \mathrm{C}$ & Exon8 & $\nabla 10 \%[25]$ & $1 / 1$ \\
\hline c. $1497 \mathrm{G} \bowtie \mathrm{A}$ & W499X & Exon8 & Nil & $1 / 1$ \\
\hline Total & & & & $132 / 66$ \\
\hline
\end{tabular}




\begin{tabular}{|c|c|c|c|c|}
\hline \multicolumn{2}{|l|}{ characteristics } & $46 X Y(n \otimes 32)$ & $46 X X(n \otimes 36)$ & $\mathrm{P}$ \\
\hline \multicolumn{2}{|c|}{ age at the assessment (year) } & $23.00(19.00,26.50)$ & $25.50(20.25,28.75)$ & 0.204 \\
\hline \multirow{2}{*}{$\begin{array}{l}\text { BMI } \\
\text { categories }\end{array}$} & normal weight & 13 & 19 & \multirow[t]{2}{*}{0.341} \\
\hline & Overweight & 19 & 17 & \\
\hline \multirow{4}{*}{$\begin{array}{l}\text { hypertension } \\
\text { grade* }\end{array}$} & Normotensive & 1 & 2 & \multirow[t]{4}{*}{0.394} \\
\hline & Grade 1 & 3 & 3 & \\
\hline & Grade 2 & 13 & 8 & \\
\hline & Grade 3 & 15 & 23 & \\
\hline \multirow{4}{*}{$\begin{array}{l}\text { hypokalemia } \\
\text { grade* }\end{array}$} & Normal potassium & 8 & 9 & \multirow[t]{4}{*}{0.183} \\
\hline & Mild hypokalemia & 11 & 5 & \\
\hline & $\begin{array}{l}\text { Moderate } \\
\text { hypokalemia }\end{array}$ & 5 & 6 & \\
\hline & $\begin{array}{l}\text { Severe } \\
\text { hypokalemia }\end{array}$ & 8 & 16 & \\
\hline \multicolumn{2}{|c|}{ Sodium (mmol/L) ${ }^{b}$} & $140.00(139.00,141.75)$ & $141.00(139.00,143.00)$ & 0.358 \\
\hline \multicolumn{2}{|c|}{ potassium $(\mathrm{mmol} / \mathrm{L})^{\mathrm{b}}$} & $3.18(2.48,3.45)$ & $2.75(2.20,3.55)$ & 0.377 \\
\hline \multicolumn{2}{|c|}{ 17-OHP (ng/ml) } & $0.28(0.12,0.74)$ & $0.40(0.20,0.78 \rrbracket$ & 0.261 \\
\hline \multicolumn{2}{|l|}{$\mathrm{P}(\mathrm{ng} / \mathrm{ml})$} & $9.33 \pm 5.88$ & $10.31 \pm 6.89$ & 0.534 \\
\hline \multicolumn{2}{|l|}{ E2 (pg/ml) } & $12.01(4.40,19.83)$ & $13.84(6.85,24.05)$ & 0.400 \\
\hline \multicolumn{2}{|l|}{$\mathrm{T}(\mathrm{ng} / \mathrm{ml})$} & $0.09(0,0.26)$ & $0.06(0,0.22)$ & 0.589 \\
\hline \multicolumn{2}{|l|}{ FSH (IU/L) } & $74.33(51.45,116.81)$ & $69.55(31.67,89.46)$ & 0.161 \\
\hline \multicolumn{2}{|l|}{ LH (IU/L) } & $32.91(22.85,53.88)$ & $27.77(20.75,38.05)$ & 0.067 \\
\hline \multicolumn{2}{|c|}{ ACTH $(\mathrm{pg} / \mathrm{mL}) \#$} & $137.30(75.95,274.00)$ & $122.00(82.45,193.00)$ & 0.572 \\
\hline \multicolumn{2}{|l|}{$F(\mu \mathrm{g} / \mathrm{dl}) \#$} & $0.63(0.32,1.10 \rrbracket$ & $0.95(0.45,1.73 \rrbracket$ & 0.182 \\
\hline
\end{tabular}

Normal range: Sodium:135-145 mmol/L, Potassium:3.5-5.5 mmol/L,ACTH: 0-46pg/ml, F:4-22.3ug/dl, 17OHP: 0.31-2.17(M); 0.10-0.80ng/ml(F);P:0.10-0.84ng/ml(M),0.38-2.28ng/ml(F);E2:囚47pg/ml(M), 27$122 \mathrm{pg} / \mathrm{ml}(\mathrm{F}) ; \mathrm{T}: 1.75-7.81 \mathrm{ng} / \mathrm{ml}(\mathrm{M}), 0.10-0.75 \mathrm{ng} / \mathrm{ml}(\mathrm{F}) ; \mathrm{FSH}: 1.27-19.26 \mathrm{IU} / \mathrm{L}(\mathrm{M}), \mathbb{Q} 10 \mathrm{IU} / \mathrm{L}(\mathrm{F}) ; \mathrm{LH}: 1.24-$ 8.62IU/L(M), 2.12-10.89IU/L(F)

Abbreviation:17-OHP: 17-hydroxyprogesterone, T: testosterone, P: progesterone, E2: estradiol, FSH: follicle stimulating hormone, LH: luteinizing hormone, ACTH: adrenocorticotropic hormone, F: cortisol 
\#: Plasma ACTH and cortisol concentrations measured at 8 a.m.

*: the potassium grade and hypertension grade were classified according to the most severe hypertension and the lowest potassium concentration ever measured or tested

b: the value of potassium concentration and sodium concentration corresponding to the most severe hypokalemia

Table 3 Comparison of clinical characteristics and laboratory indicators of 17-OHD patients between HMOD group and non-HMOD group 


\begin{tabular}{|c|c|c|c|c|}
\hline \multirow{2}{*}{\multicolumn{2}{|c|}{ Characteristics }} & HMOD Group & NO HMOD Group & $P$ \\
\hline & & $(\mathrm{n} \otimes 32)$ & $(n \rrbracket 36)$ & \\
\hline \multicolumn{2}{|c|}{ age at the assessment (year) } & $26.00(24.00,30.00)$ & $20.50(19.00,25.00)$ & $\begin{array}{l}\square \\
0.001\end{array}$ \\
\hline \multirow{2}{*}{$\begin{array}{l}\text { BMI } \\
\text { categories }\end{array}$} & normal weight & 15 & 17 & \multirow{2}{*}{1.000} \\
\hline & overweight & 17 & 19 & \\
\hline \multirow{4}{*}{$\begin{array}{l}\text { hypertension } \\
\text { grade* }^{\star}\end{array}$} & Normotensive & 0 & 3 & \multirow{4}{*}{0.001} \\
\hline & Grade 1 & 0 & 6 & \\
\hline & Grade 2 & 4 & 17 & \\
\hline & Grade 3 & 28 & 10 & \\
\hline \multirow{4}{*}{$\begin{array}{l}\text { hypokalemia } \\
\text { grade* }^{*}\end{array}$} & $\begin{array}{l}\text { Normal } \\
\text { potassium }\end{array}$ & 0 & 22 & \multirow[t]{4}{*}{$\begin{array}{l}0.001 \\
0\end{array}$} \\
\hline & $\begin{array}{l}\text { Mild } \\
\text { hypokalemia }\end{array}$ & 5 & 14 & \\
\hline & $\begin{array}{l}\text { Moderate } \\
\text { hypokalemia }\end{array}$ & 8 & 7 & \\
\hline & $\begin{array}{l}\text { Severe } \\
\text { hypokalemia }\end{array}$ & 17 & 7 & \\
\hline \multicolumn{2}{|l|}{ 17-OHP (ng/ml) } & $0.32(0.16,0.72)$ & $0.46(0.16,0.82)$ & 0.422 \\
\hline \multicolumn{2}{|l|}{$\mathrm{P}(\mathrm{ng} / \mathrm{ml})$} & $8.95 \pm 5.40$ & $10.65 \pm 7.16$ & 0.280 \\
\hline \multicolumn{2}{|l|}{ E2 (pg/ml) } & $10.01(4.67,24.93)$ & $12.95(7.40,19.83)$ & 0.676 \\
\hline \multicolumn{2}{|l|}{$\mathrm{T}(\mathrm{ng} / \mathrm{ml})$} & $0.06(0,0.19)$ & $0.09(0.01,0.28)$ & 0.449 \\
\hline \multicolumn{2}{|l|}{ FSH (IU/L) } & $76.80(60.90,99.38)$ & $56.15(25.22,99.86)$ & 0.102 \\
\hline \multicolumn{2}{|l|}{ LH (IU/L) } & $29.83(22.85,38.83)$ & $31.87(17.89,48.51)$ & 0.867 \\
\hline \multicolumn{2}{|l|}{$\mathrm{ACTH}(\mathrm{pg} / \mathrm{mL}) \#$} & $128.55(86.18,228.50)$ & $129.80(75.08,271.50)$ & 0.712 \\
\hline \multicolumn{2}{|l|}{$\mathrm{F}(\mu \mathrm{g} / \mathrm{dl}) \#$} & $0.80(0.46,1.19)$ & $0.71(0.33,1.82)$ & 0.959 \\
\hline \multicolumn{2}{|l|}{$\mathrm{SBP}(\mathrm{mmHg})^{\mathrm{a}}$} & $168.84 \pm 19.37$ & $157.44 \pm 19.66$ & 0.019 \\
\hline \multicolumn{2}{|l|}{$\mathrm{DBP}(\mathrm{mmHg})^{\mathrm{a}}$} & $116.97 \pm 14.24$ & $103.19 \pm 14.98$ & 0.001 \\
\hline \multicolumn{2}{|l|}{ potassium $(\mathrm{mmol} / \mathrm{L})^{\mathrm{b}}$} & $2.43 \pm 0.61$ & $3.39 \pm 0.77$ & 0.001 \\
\hline \multicolumn{2}{|l|}{$\operatorname{Sodium}(\mathrm{mmol} / \mathrm{L})^{b}$} & $140.00(139.00,143.00)$ & $140.50(139.00,142.00)$ & 0.660 \\
\hline
\end{tabular}




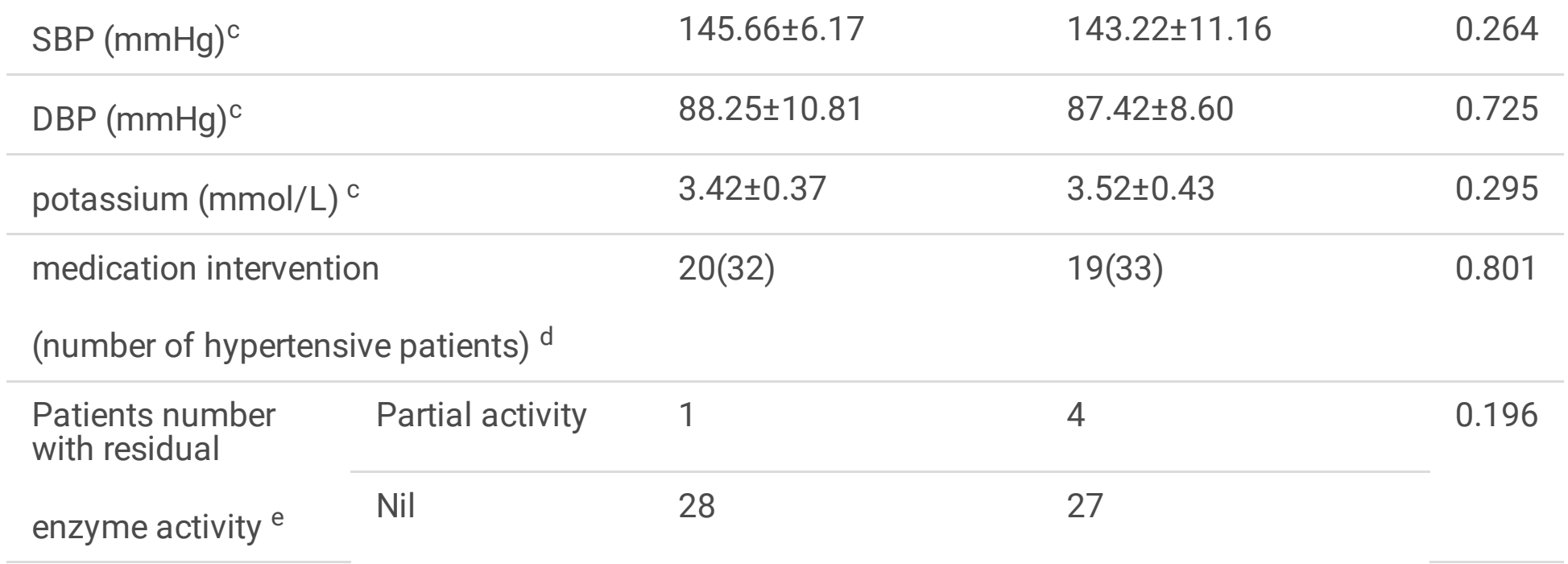

Normal range: Sodium:135-145 mmol/L, Potassium:3.5-5.5 mmol/L,ACTH: 0-46pg/ml, F:4-22.3ug/dl, 17OHP: 0.31-2.17(M); 0.10-0.80ng/ml(F);P:0.10-0.84ng/ml(M),0.38-2.28ng/ml(F);E2: \47pg/ml(M), 27-

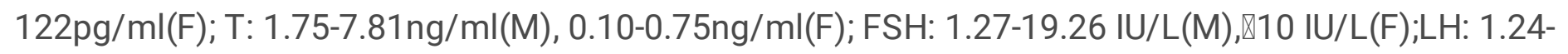
8.62IU/L(M), 2.12-10.89IU/L(F)

Abbreviation:17-OHP: 17-hydroxyprogesterone, T: testosterone, P: progesterone, E2: estradiol, FSH: follicle stimulating hormone, LH: luteinizing hormone, ACTH: adrenocorticotropic hormone, F: cortisol \#: Plasma ACTH and cortisol concentrations measured at 8 a.m.

*: the potassium grade and the hypertension grade were classified respectively according to the most severe hypertension and the lowest potassium concentration ever measured or tested

a: the value of systolic blood pressure,diastolic blood pressure corresponding to the most severe hypertension

b. the value of potassium concentration and sodium concentration corresponding to the most severe hypokalemia

c: the systolic blood pressure,diastolic blood pressure and potassium concentration at the assessment of HMOD

$d$ : the patients number receiving antihypertensive agents or glucocorticoid and the total number of hypertensive patients

e: the patients number with different residual enzyme activity, nil: enzymatic activity abolished completely, partial activity: residual enzyme function remained

Table 4 clinical manifestations of 32 17-OHD patients with HMOD 
Patients No. karyotype Age SBP DBP Grade\# HMOD related organ damage

\begin{tabular}{|c|c|c|c|c|c|c|c|c|}
\hline & & (yea & & & & Heart & Kidney & Retina \\
\hline 6 & $46 X Y$ & 18 & 170 & 130 & 3 & & CKD & $\mathrm{RP}$ \\
\hline 25 & $46 X Y$ & 20 & 200 & 160 & 3 & & ALB & $\mathrm{RP}$ \\
\hline 31 & $46 X Y$ & 25 & 180 & 100 & 3 & LVH & & \\
\hline 33 & $46 X Y$ & 22 & 170 & 120 & 3 & LVH & CKD & \\
\hline 35 & $46 X Y$ & 23 & 210 & 140 & 3 & LVH & & $\mathrm{RP}$ \\
\hline 36 & $46 X Y$ & 24 & 150 & 100 & 2 & LVH CHF & & \\
\hline 40 & $46 X Y$ & 28 & 160 & 110 & 3 & & CKD & $\mathrm{RP}$ \\
\hline 41 & $46 X Y$ & 29 & 190 & 140 & 3 & LVH & & $\mathrm{RP}$ \\
\hline 42 & $46 X Y$ & 30 & 140 & 100 & 2 & & & $\mathrm{RP}$ \\
\hline 43 & $46 X Y$ & 45 & 130 & 105 & 2 & & ALB & $\mathrm{RP}$ \\
\hline 44 & $46 X Y$ & 59 & 170 & 110 & 3 & LVH & CKD & $\mathrm{RP}$ \\
\hline 47 & $46 X X$ & 18 & 150 & 100 & 2 & LVH & ALB & \\
\hline 49 & $46 X X$ & 26 & 170 & 110 & 3 & & ALB & \\
\hline 51 & $46 X X$ & 18 & 180 & 120 & 3 & LVH & & \\
\hline 55 & $46 X X$ & 24 & 175 & 110 & 3 & & CKD & \\
\hline 61 & $46 X X$ & 30 & 160 & 110 & 3 & & & $\mathrm{RP}$ \\
\hline 65 & $46 X X$ & 23 & 190 & 120 & 3 & LVH & CKD & $\mathrm{RP}$ \\
\hline 66 & $46 X X$ & 25 & 160 & 120 & 3 & & & $\mathrm{RP}$ \\
\hline 67 & $46 X X$ & 25 & 150 & 115 & 3 & & CKD & $\mathrm{RP}$ \\
\hline 69 & $46 X X$ & 25 & 160 & 120 & 3 & LVH & CRF & $\mathrm{RP}$ \\
\hline 71 & $46 X X$ & 25 & 140 & 110 & 3 & & & $\mathrm{RP}$ \\
\hline 72 & $46 X X$ & 26 & 180 & 110 & 3 & & CKD & \\
\hline 75 & $46 X X$ & 26 & 158 & 118 & 3 & & ALB & $\mathrm{RP}$ \\
\hline 76 & $46 X X$ & 26 & 150 & 110 & 3 & & & $\mathrm{RP}$ \\
\hline 77 & $46 X X$ & 27 & 200 & 150 & 3 & LVH & & \\
\hline 79 & $46 X X$ & 28 & 180 & 130 & 3 & & CKD & $\mathrm{RP}$ \\
\hline 80 & $46 X X$ & 29 & 180 & 110 & 3 & & & RP \\
\hline
\end{tabular}




\begin{tabular}{lllllllll}
83 & $46 X X$ & 35 & 170 & 110 & 3 & & CKD & RP \\
\hline 84 & $46 X X$ & 32 & 140 & 110 & 3 & & & RP \\
\hline 85 & $46 X X$ & 32 & 170 & 120 & 3 & LVH & & \\
\hline 86 & $46 X X$ & 37 & 190 & 110 & 3 & & ALB & RP \\
\hline 87 & $46 X X$ & 37 & 180 & 115 & 3 & & ALB & RP
\end{tabular}

ALB: Albuminuria; CKD: Chronic kidney disease; CRF: chronic renal failure; LVH: left ventricular hypertrophy; CHF: chronic heart failure; SBP: systolic blood pressure; DBP: diastolic blood pressure; IS: ischemic stroke; HS: hemorrhagic stroke; RP: Retinopathy.

\#: hypertension grade

Table 5 Risk factors associated with HMOD in 17-OHD patients 
Factor Logistic univariate regression

OR $(95 \% \mathrm{Cl})$

OR $(95 \% \mathrm{Cl})$

\begin{tabular}{|c|c|c|c|c|}
\hline $\begin{array}{l}\text { age at the } \\
\text { assessment(year) }\end{array}$ & $1.316(1.143,1.516)$ & 0.001 & $1.272(1.057,1.530)$ & 0.011 \\
\hline BMI categories & $1.014(0.391,2.633)$ & 0.977 & & \\
\hline hypertension grade* & $12.915 \llbracket 3.731,44.706 \rrbracket$ & $\begin{array}{l}\square \\
0.001\end{array}$ & $8.734(1.796,42.473)$ & 0.007 \\
\hline hypokalemia grade* & $3.487(1.983,6.131)$ & $\begin{array}{l}\square \\
0.001\end{array}$ & $2.735(1.315,5.688)$ & 0.007 \\
\hline $170 \mathrm{HP}(\mathrm{ng} / \mathrm{ml})$ & $0.514(0.170,1.556)$ & 0.239 & & \\
\hline $\mathrm{T}(\mathrm{ng} / \mathrm{ml})$ & $0.647(0.106,3.940)$ & 0.636 & & \\
\hline$P(p g / m l)$ & $0.958(0.887,1.035)$ & 0.278 & & \\
\hline $\mathrm{E} 2(\mathrm{pg} / \mathrm{ml})$ & $0.996(0.965,1.028)$ & 0.793 & & \\
\hline $\mathrm{FSH}(\mathrm{IU} / \mathrm{L})$ & $1.007(0.996,1.019)$ & 0.219 & & \\
\hline LH (IU/L) & $0.990(0.964,1.017)$ & 0.473 & & \\
\hline ACTH $(\mathrm{pg} / \mathrm{mL})$ & $1.000(0.996,1.004)$ & 0.894 & & \\
\hline$F(\mu \mathrm{g} / \mathrm{dl})$ & $0.816(0.606,1.099)$ & 0.181 & & \\
\hline potassium $(\mathrm{mmol} / \mathrm{L})^{\mathrm{c}}$ & $0.520(0.154,1.754)$ & 0.291 & & \\
\hline $\operatorname{SBP}(\mathrm{mmHg})^{\mathrm{c}}$ & $1.030(0.976,1.087)$ & 0.275 & & \\
\hline $\mathrm{DBP}(\mathrm{mmHg})^{\mathrm{c}}$ & $1.009(0.960,1.061)$ & 0.720 & & \\
\hline $\begin{array}{l}\text { medication intervention } \\
d\end{array}$ & $1.154(0.434,3.067)$ & 0.774 & & \\
\hline enzyme activity ${ }^{\mathrm{e}}$ & $0.186(0.020,1.697)$ & 0.136 & & \\
\hline
\end{tabular}

*: the potassium grade and the hypertension grade were classified respectively according to the most severe hypertension and the lowest potassium concentration ever measured or tested

c: the systolic blood pressure,diastolic blood pressure and potassium concentration at the assessment of HMOD

$d$ : the patients number receiving antihypertensive agents or glucocorticoid

e: the patients number with different residual enzyme activity 
Figures

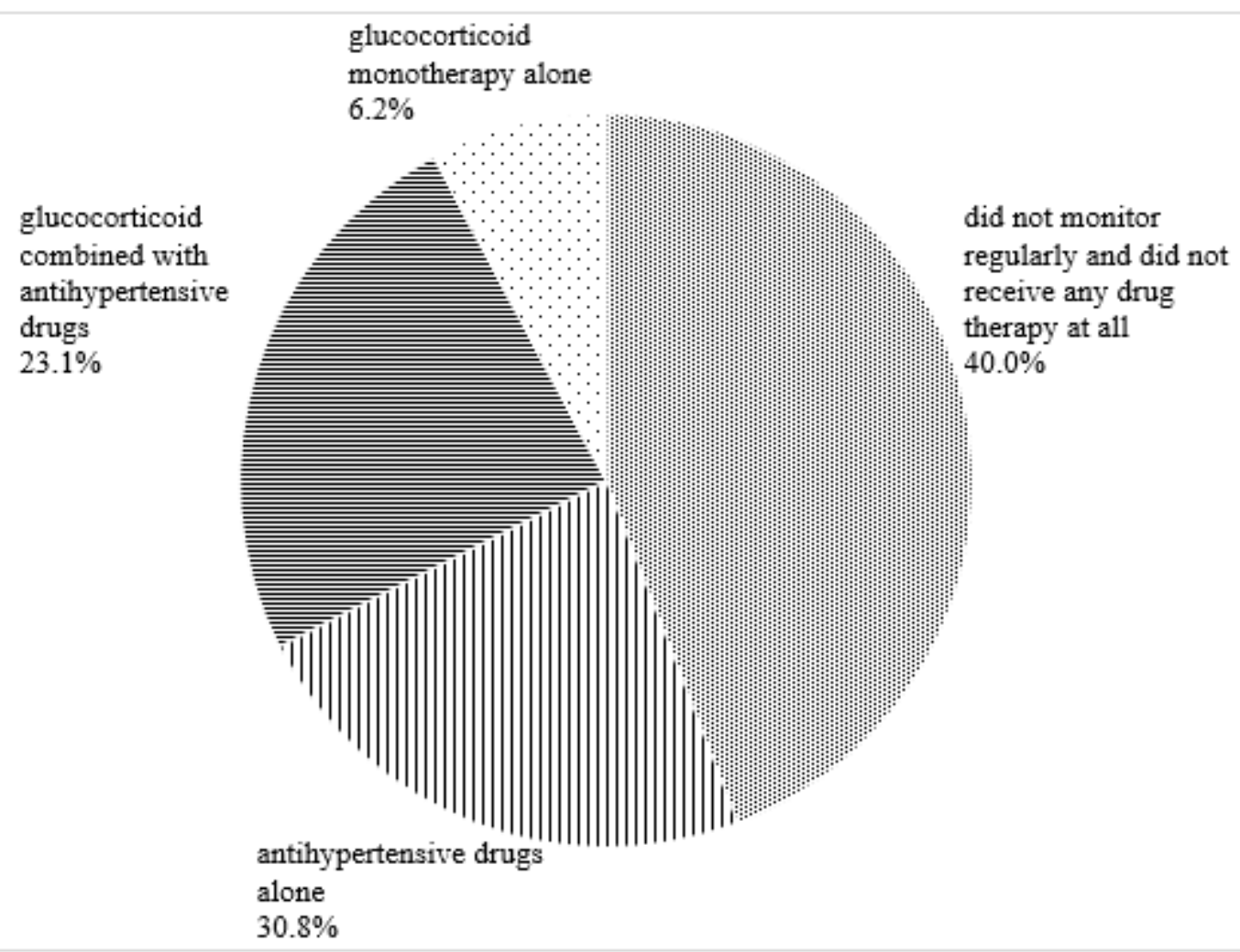

Figure 1

Percentage of patients on different hypertension treatment regimens before the assessment of HMOD in 17-OHD patients.

\section{Supplementary Files}

This is a list of supplementary files associated with this preprint. Click to download.

- Supplementarylnformation.pdf 